\title{
Detection of piscine orthoreoviruses (PRV-1 and PRV-3) in Atlantic salmon and rainbow trout farmed in Germany
}

Adamek, Mikolaj; Hellmann, John; Flamm, Agnes; Teitge, Felix; Vendramin, Niccolò; Fey, Daniel; Riße, Karin; Blakey, Franziska; Rimstad, Espen; Steinhagen, Dieter

\section{Published in:}

Transboundary and Emerging Diseases

Link to article, DOI:

10.1111/tbed.13018

Publication date:

2019

Document Version

Peer reviewed version

Link back to DTU Orbit

\section{Citation $(A P A)$ :}

Adamek, M., Hellmann, J., Flamm, A., Teitge, F., Vendramin, N., Fey, D., Riße, K., Blakey, F., Rimstad, E., \& Steinhagen, D. (2019). Detection of piscine orthoreoviruses (PRV-1 and PRV-3) in Atlantic salmon and rainbow trout farmed in Germany. Transboundary and Emerging Diseases, 66(1), 14-21. https://doi.org/10.1111/tbed.13018

\section{General rights}

Copyright and moral rights for the publications made accessible in the public portal are retained by the authors and/or other copyright owners and it is a condition of accessing publications that users recognise and abide by the legal requirements associated with these rights.

- Users may download and print one copy of any publication from the public portal for the purpose of private study or research.

- You may not further distribute the material or use it for any profit-making activity or commercial gain

- You may freely distribute the URL identifying the publication in the public portal 
DR. MIKOLAJ ADAMEK (Orcid ID : 0000-0003-4890-3164)

Article type : Rapid Communication

Detection of piscine orthoreoviruses (PRV-1 and PRV-3) in Atlantic salmon and rainbow trout farmed in Germany.

\section{Running title: PRV-1 and PRV-3 in salmonids in Germany.}

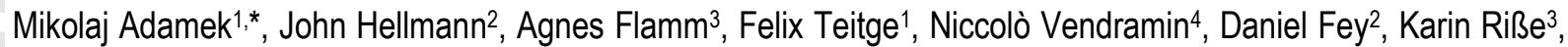
Franziska Blakey³, Espen Rimstad5 5 , Dieter Steinhagen¹.

${ }^{1}$ Fish Disease Research Unit, Institute for Parasitology, University of Veterinary Medicine, Hannover, Germany 2 Department Fisheries Ecology, North Rhine Westphalian State Agency for Nature, Environment and Consumer Protection, Albaum, Germany

${ }^{3}$ Hesse State Laboratory, Control of Fish Diseases, Giessen, Germany

${ }^{4}$ Fish Diseases, Division for Diagnostics \& Scientific Advice, National Veterinary Institute, Technical University of Denmark, Lyngby, Denmark

${ }^{5}$ Department of Food Safety and Infection Biology, Norwegian University of Life Sciences, Oslo, Norway

${ }^{*}$ Corresponding author. Tel.:+49 511 9538579; fax: +49 5119538587.

Postal address: Fish Disease Research Unit, Centre of Infectious Diseases, University of Veterinary Medicine Hannover, Bünteweg 17, D-30559 Hannover, Germany

E-mail address: mikolaj.adamek@tiho-hannover.de; marana@interia.pl

This article has been accepted for publication and undergone full peer review but has not been through the copyediting, typesetting, pagination and proofreading process, which may lead to differences between this version and the Version of Record. Please cite this article as doi: 10.1111/tbed.13018

This article is protected by copyright. All rights reserved. 


\section{Summary}

Piscine orthoreoviruses (PRVs) are emerging pathogens causing circulatory disorders in salmonids. PRV-1 is the etiological cause of heart and skeletal muscle inflammation (HSMI) in farmed Atlantic salmon (Salmo salar), characterized by epicarditis, inflammation and necrosis of the myocardium, myositis and necrosis of red skeletal muscle. In 2017, two German breeding farms for Atlantic salmon and rainbow trout (Oncorhynchus mykiss), respectively, experienced disease outbreaks with mortalities of $10 \%$ and $20 \%$. The main clinical signs were exhaustion and lethargic behavior. During examinations, PRV-1 in the salmon and the PRV-3 in trout were detected for the first time in Germany. Further analyses also indicated the presence of Aeromonas salmonicida in internal tissues of both species. While PRV-1 could be putatively linked with the disease in Atlantic salmon, most of the rainbow trout suffered from an infection with A. salmonicida and not with PRV-3. Interestingly, the sequence analysis suggests that the German PRV-3 isolate is more similar to a Chilean PRV-3 isolate from Coho salmon (Oncorhynchus kisutch) than to PRV-3 from rainbow trout from Norway. This indicates a wide geographic distribution of this virus or dispersal by global trade. These findings indicate that infections with PRVs should be considered when investigating disease outbreaks in salmonids.

Keywords: piscine orthoreoviruses, PRV, PRV-1, PRV-Om, PRV-3, heart and skeletal muscle inflammation, HSMI, Aeromonas salmonicida.

\section{Introduction}

Piscine orthoreovirus (PRV) is an emerging pathogen causing circulatory disorders in salmonids. PRV-1 was the first piscine orthoreovirus described and originally found to be associated with the disease heart and skeletal muscle inflammation (HSMI) in farmed Atlantic salmon (Salmo salar) in Norway (Palacios et al., 2010, Finstad et al., 2012). PRV-1 is ubiquitous in the sea phase of farmed Atlantic salmon, thus questioning its etiological role in HSMI. However, the causal relationship was later verified (Wessel et al., 2017). The histopathologic changes of HSMI are characterized by epicarditis, inflammation and necrosis of the compact layer of the myocardium, myositis and necrosis of red skeletal muscle (Kongtorp et al., 2004). In Atlantic salmon, an accumulated mortality of $20 \%$ has been reported, but most often it is considerably lower. Since its first discovery, PRV-1 has been detected in several salmonid species from the Salmo and Oncorhynchus genera in multiple

This article is protected by copyright. All rights reserved. 
locations, including Northern Europe, Canada, USA, and Chile (Garver et al., 2016, Marty et al., 2015, Kibenge et al., 2013). Recently, a subtype of PRV, PRV-Om, was detected in rainbow trout (Oncorhynchus mykiss) in Norway. This variant showed about $85 \%$ nucleotide identity to PRV-1 on the S1 segment. Similar to PRV-1, PRVOm was also associated with an HSMI-like disease (Olsen et al., 2015). A closely related viral strain was also detected in Coho salmon (Oncorhynchus kisutch) in Chile (Godoy et al., 2016). Coho salmon is also susceptible to another subtype of PRV detected in Japan, PRV-2, causing the erythrocytic inclusion body syndrome (EIBS) (Takano et al., 2016). In line with the nomenclature proposed by Dhamotharan et al., (2018), we use PRV-3 to name the PRV described from rainbow trout (previously named PRV-Om).

PRV infections could be involved in reduced performance of infected fish (Morton et al., 2017, Lund et al., 2017). Therefore, PRV can be considered as a threat to aquaculture and the aquatic environment. German aquaculture, with a significant production of rainbow trout and conservation programs for Atlantic salmon in several river systems, is potentially vulnerable to the impact caused by these virus infections. The common trading of fertilized eggs and live animals, both intra- and inter-continentally, makes the potential spread of aquatic viruses rapid and broad (Crane and Hyatt, 2011). Therefore, we decided to evaluate the prevalence of piscine orthoreoviruses in German salmonid populations with indications of circulatory system failure.

PRV-1 replicates in cardiomyocytes and erythrocytes (Finstad et al., 2012, Finstad et al., 2014). Currently, it is not possible to cultivate the virus in cell culture monolayers: Thus, laboratory tests for conducting surveillance and diagnostics mostly rely on specific reverse-transcriptase quantitative PCR (RT-qPCR) protocols (Palacios et al., 2010, Olsen et al., 2015) supported by immunohistochemistry. In 2017, a two-step RT-PCR based screening for PRV-1 and PRV-3 was initiated at the Fish Disease Research Unit, University of Veterinary Medicine in Hannover, Germany. Additional viruses (salmonid alphavirus type 2, SAV-2, piscine myocarditis virus, PMCV and Atlantic salmon calicivirus, ASCV) were included in the examinations due to their associations with myocardial diseases (Wiik-Nielsen et al., 2016).

\section{Material and Methods}

Outbreak 1: In 2017 a German farm specialized in breeding salmonids (Atlantic salmon, tiger trout Salmo trutta $\times$ Salvelinus fontinalis and rainbow trout) experienced a disease outbreak followed by mild chronic health problems spread over a period of two to three months (March till May) in Atlantic salmon and tiger trout 
kept in fresh water. This led to cumulative mortalities estimated as being 5 to $10 \%$ of the affected stocks. Affected fish showed signs of exhaustion, reduced mobility and lethargic behavior. During necropsies, sporadic bleedings in the muscles and the pericardium were observed. Samples from these fish were examined for the presence of viral infection by cultural methods as described below. Since these analyses gave negative results, one Atlantic salmon and five tiger trouts (Salmo trutta $\times$ Salvelinus fontinalis) were sampled for molecular diagnostics of virus infection. Over a period of six months post the initial outbreak, further Atlantic salmon individuals were included in this analysis. The complete panel of specimen collected for laboratory investigations consisted of $n=34$ Atlantic salmon (with a body length of $17-52 \mathrm{~cm}$ ) and $\mathrm{n}=5$ tiger trout (with a body length of $20-21 \mathrm{~cm}$ ) (Table 1). Furthermore, wild Atlantic salmon ( $n=4$; with a body length of $62-101 \mathrm{~cm}$ ) captured in rivers in western Germany were also included in the analyses.

Outbreak 2: In the same year, a rainbow trout farm in central Germany experienced a disease outbreak in early summer, lasting for two weeks and affecting all age groups excluding the fry. Diseased fish showed darkening of the skin, lethargic behavior and the mortality rate reached $20 \%$ in affected stocks. The internal clinical signs were similar to those seen in Atlantic salmon from Outbreak 1, with hemorrhaging in the muscles and the heart. Eight diseased fish from the group subjected to final ongrowing (16 months old), with a body length of $15-31 \mathrm{~cm}$, were sampled for analysis (Table 2).

In both cases, the fish samples were subjected to classical bacteriologic and virologic culturing test, and analyzed for the presence of nucleic acids of PRV-1, PRV-3, SAV-2, PMCV and ASCV as described below.

Tissue samples (heart, spleen, kidney, head kidney) were collected into RNAlater from all fish and total RNA was extracted from $50 \mathrm{mg}$ of selected tissue using TRI-Reagent (Sigma) in accordance with the manufacturer's instructions. cDNA was transcribed from 900-1000 ng total RNA using the Maxima First Strand cDNA Synthesis Kit (Thermo Fisher Scientific). cDNA samples were diluted 1:20 with nuclease-free water prior to end-point or quantitative PCR analysis. The end-point assays were performed using the KAPA2G Robust Hot Start PCR kit (Sigma) in accordance with the manufacturer's instructions. The reaction contained: 1× KAPA2G buffer A, $0.2 \mu \mathrm{M}$ of each primer, $0.2 \mathrm{mM}$ of each dNTP, 1 U of KAPA2G Robust Hot Start Polymerase, $5.0 \mu \mathrm{l} 20 \mathrm{x}$ diluted cDNA and nuclease-free water to a final volume of $20 \mu$. The amplification program included an initial denaturation at $95^{\circ} \mathrm{C}$ for $5 \mathrm{~min}$, followed by 45 cycles of denaturation at $95^{\circ} \mathrm{C}$ for $30 \mathrm{~s}$, annealing at $60{ }^{\circ} \mathrm{C}$ for 30 s and elongation at $72{ }^{\circ} \mathrm{C}$ for $60 \mathrm{~s}$. Primer sequences are listed in Supplementary Table 1. After electrophoretic

This article is protected by copyright. All rights reserved. 
separation in a $1 \%$ agarose gel containing $1 \times$ Gel Red (Biotium) fluorescent DNA stain and visualization in 302nm UV light, the PCR products were used for Sanger's direct sequencing performed by LGC Genomics (Berlin, Germany). The obtained nucleotide sequences, $787 \mathrm{bp}$ of the L1 segment of PRV- 1 and $371 \mathrm{bp}$ of the PRV-3 segment S1, were aligned with piscine orthoreovirus sequences accessible in GenBank using tools available at www.phylogeny.fr (Dereeper et al., 2008). MrBayes phylogeny (Bayesian inference) was used with Markov Chain Monte Carlo parameters set-up to 10000 generations, with tree sampling every ten generations and burn-in of 250 trees sampled.

Quantitative PCR was performed in duplicate using the Maxima SYBR Green $2 \times$ mastermix (Thermo Fisher Scientific) in a Stratagene Mx3005P cycler (Agilent). The reaction mix contained: 1× Maxima SYBR Green mastermix (with $10 \mathrm{nM}$ of ROX), $0.2 \mu \mathrm{M}$ of each primer (sequences in Supplementary Table 1), $5.0 \mu \mathrm{L}$ of $20 \mathrm{x}$ diluted cDNA and nuclease-free water to a final volume of $20 \mu \mathrm{L}$. The amplification program included an initial denaturation at $95^{\circ} \mathrm{C}$ for $10 \mathrm{~min}$, followed by 40 cycles of denaturation at $95^{\circ} \mathrm{C}$ for $30 \mathrm{~s}$, annealing at $60^{\circ} \mathrm{C}$ for $30 \mathrm{~s}$ and elongation at $72{ }^{\circ} \mathrm{C}$ for $30 \mathrm{~s}$. A dissociation curve was performed at the end of each run. For the RT(q)PCRs analyses, positive controls were obtained by courtesy of Dr. Hilde Sindre from the Norwegian Veterinary Institute and of Dr. Peter Steinbauer from Tiergesundheitsdienst Bayern, Germany. In the qPCR for aeromonads $16 S$ rRNA a plasmid-based quantification of total gene copy numbers was performed as described earlier (Adamek et al., 2013).

From fish showing prominent clinical signs ( $n=10$ Atlantic salmon, $n=10$ tiger trout from Outbreak 1 and $\mathrm{n}=10$ rainbow trout from Outbreak 2), the spleen, head kidney and brain were pooled and collected in tissue culture medium (Eagle's minimum essential medium containing 10\% foetal bovine serum, $100 \mathrm{IU} \mathrm{mL}-1$ penicillin and $100 \mu \mathrm{g} \mathrm{mL}-1$ streptomycin). After homogenization, samples were inoculated into RTG-2 and EPC cell culture monolayers for detection of VHSV, IPNV, and IHNV in accordance with the "General Procedures for Virology" indicated in the AFS-FHS Blue Book (Ganzhorn and LaPatra, 1994) and EU guideline (European Commission, 2015). Additionally, spleen, liver, and kidney samples collected from the same fish were inoculated into blood agar plates incubated at $15{ }^{\circ} \mathrm{C}$ or $25^{\circ} \mathrm{C}$ for $48 \mathrm{~h}$ and observed for bacterial growth. This was followed by identification of bacterial colonies with the API 20 NE biochemical test kit (Biomerieux).

Three macroscopically affected hearts from Atlantic salmon were collected three-six months post the initial outbreak (See Table 1), fixed for histology in 4\% buffered formaldehyde, dehydrated and embedded in 
paraffin wax. Sections were cut, stained with hematoxylin-eosin, and examined with a light microscope (AxioPhot, Zeiss).

\section{Results and Discussion}

Virologic examination of samples from both outbreaks gave negative results in cell cultures, ruling out infections with VHSV, IHNV and IPNV. This also excluded any other virus which would be capable of replicating on RTG-2 or EPC cells (Ganzhorn and LaPatra, 1994). Also, the RT-PCR assays for PMCV, SAV-2 and ASCV tested all samples negative (See Tables 1 and 2). Only PRV-1 and PRV-3 were detected in Atlantic salmon and rainbow trout, respectively.

From the 34 farmed Atlantic salmon screened, seven were positive for PRV-1 (20.5\% prevalence). The virus was not found in four sampled wild salmon (Table 1). The Cq values from 25.44 to 32.31 in PRV-1 positive fish, suggested a moderate to low load with virus genome. A fish with the highest load of virus genome was sampled after the initial outbreak of the disease, while individuals collected at later time-points harbored a lower load of virus genome or gave a negative result (See Table 1). As shown in earlier infection studies, clinical HSMI is related to high virus load early in the disease progression (Finstad et al., 2014, Wessel et al., 2017), while fish may become asymptomatically persistent carriers of the virus at later stages. Microscopically, only three fish were evaluated: one PRV-1 positive and two PRV-1 negative. A mild myocarditis of compact myocardium, often located near the border of the spongy myocardium of the ventricle, was noticed in one PRV-1 positive (Supplementary Figure 1) and one of the PRV-1 negative fish. The second fish negative for PRV-1 showed mild epicarditis (data not shown), indicating that the cause of the heart pathology remained uncertain. PRV-1 was the only virus detected in the affected Atlantic salmon. However, further analyses revealed that the clinical signs displayed by the fish could have a dual etiology related to bacterial coinfection, which could influence the pathohistologic evaluation. While during initial sampling the only one Atlantic salmon sampled was positive for PRV-1, with the highest virus load recorded in the whole screening, several tiger trout from the initial sampling and Atlantic salmon individuals collected at further time-points were PRV-1 negative and instead seemed to have suffered from a systemic infection with Aeromonas salmonicida ssp. salmonicida, which was found during routine bacteriologic diagnostics (Hellmann, unpublished observation). The bacterial infection was confirmed by RTqPCR analysis for aeromonads $16 \mathrm{~S}$ rRNA. With this RT-qPCR we were able to demonstrate a high bacterial load

This article is protected by copyright. All rights reserved. 
in some internal tissues in individual fish specimens (See Table 1): for instance, at initial sampling two clinically most affected tiger trout harbored 1,425,534 and 95,072,800 copies of aeromonads rRNA, respectively. Interestingly, in samples from all but one PRV-1 positive Atlantic salmon the amounts of bacteria were very low (9 to 980 copies of aeromonads rRNA) and thus most likely cannot be associated with the clinical signs of infection observed in these individuals. Therefore, we hypothesize that PRV-1 could be the causative agent of the initial disease outbreak in Atlantic salmon. The virus persisted in the population, while some Atlantic salmon acquired an infection with $A$. salmonicida. This could have been spread by tiger trout raised at the same farm because some of the tiger trout harbored a very high bacterial load during initial sampling (See Table 1). At this time, the bacterial load in Atlantic salmon was low (See Table 1). The presence of a small amount of aeromonads rRNA in all samples is in line with earlier results showing that $A$. salmonicida DNA was commonly found in blood of Atlantic salmon (Mooney et al., 1995). Nonetheless, it could also be related to a contamination during sample collection, since aeromonads are ubiquitous in the microbiome associated with the fish's skin or gills. However, it is also possible that PRV-1 and $A$. salmonicida infections existed in parallel in Atlantic salmon from the start of the outbreak and a coinfection with both pathogens was the cause of the initial health problem in the farm.

Nevertheless, this is the first confirmation of PRV-1 in Germany. In a phylogenetic analysis of the L1 sequence fragment, the German isolate (GenBank ID: MG770489) showed the highest similarity to the Norwegian isolate NOR 2012-V3621 (See Figure 1A). Taking into account the widespread distribution of this virus in farmed and wild populations of Atlantic salmon (Garver et al., 2016, Marty et al., 2015, Kibenge et al., 2013), the detection of this virus in Atlantic salmon in Germany is not surprising. The results from a much wider screening performed in fish from Norwegian rivers showed that the virus could be found in $13.4 \%$ of wild Atlantic salmon, and in $24.0 \%$ of salmon cultured for the enhancement of natural stocks (Garseth et al., 2013). A screening performed in British Columbia (BC, Canada) indicated a prevalence of PRV-1 of $1.7-100 \%$ in virus positive populations (Marty et al., 2015). Similarly, in the neighboring states of BC, in Washington and Alaska (USA), the prevalence of infection ranged from $2 \%$ to $73 \%$ in 25 PRV positive stocks, with Coho and Chinook salmon (Oncorhynchus tshawytscha) being the species found most frequently positive for PRV-1 (Purcell et al., 2018). Importantly, PRV-1 infection of salmonids may cause heart pathology which may impact migration success to their reproduction sites as recently suggested from studies on Pacific salmonids in Canada (Morton et al., 2017). In this recent research study, a negative correlation was observed between the amount of PRV-1 positive

This article is protected by copyright. All rights reserved. 
Pacific salmons (Oncorhynchus spp.) at a particular spawning site and the difficulty to reach this site by upriver migration. Although speculative, these results could indicate that a PRV-1 infection might pose a challenge to the migratory and reproductive success of infected individuals (Morton et al., 2017). Reduced hypoxia tolerance and cardiac performance has been shown for fish with experimentally-induced HSMI (Lund et al., 2017). The possible influence of PRV-1 infection on the migration success of returning anadromous salmonids should be monitored and modeled more closely for the German populations.

While PRV-1 seems to be common in several salmonid populations, much less is known about the prevalence of PRV-3 in salmonid aquaculture. In a recent experimental infection, the virus presence was strongly associated with the development of heart pathology in rainbow trout (Hauge et al., 2017). The detection of this virus in two of eight rainbow trout tested from the second farm, with $\mathrm{Cq}$ values of 23.22 and 26.44 in heart samples, confirms the presence of this virus in the trout population in Germany. This is the third country (after Norway and Chile) where PRV-3 has been described (Cartagena et al., 2018, Olsen et al., 2015). Interestingly, the phylogenetic analysis of segment S1 sequence suggests that the German PRV-3 (GenBank ID: MG770490) is more similar to the Chilean PRV-3 isolate from Coho salmon than to PRV-3 from rainbow trout from Norway (See Figure 1B). The latest phylogenetic studies on PRV-3 suggest that the newly detected isolates from Germany, Denmark, Scotland and Italy and Chile belong to a different clade (PRV-3b) than the PRV-3 isolate from Norway (PRV-3a) (Dhamotharan et al., 2018). Taken together, these results indicate that global trade with live salmonids may play a role in distributing this virus. However, at the current stage with a limited testing for PRV-3 we cannot exclude the hypothesis of potential wild reservoirs for the virus in endemic salmonid populations (Dhamotharan et al., 2018).

PRV-3 was not the only pathogen present in clinically affected rainbow trout during Outbreak 2 . Results from bacterial cultivation suggested a systemic infection with Aeromonas salmonicida ssp. salmonicida in this case as well (Flamm, unpublished observation). The RT-qPCR analysis for aeromonads $16 \mathrm{~S}$ rRNA confirmed a high bacterial load in hearts and spleens of six of eight fish with $18,200-38,104,887$ copies of aeromonads rRNA (Table 2). Combined, the findings of bacterial cultivation and qPCR strongly suggested that furunculosis and not PRV-3 could be the main cause of the clinical signs and the losses observed in the rainbow trout of this case. After the initial detection of PRV-3 we screened eight additional rainbow trout farms from four federal states of Germany and this resulted in the detection of PRV-3 one further farm in 2018, in a different state than the initial

This article is protected by copyright. All rights reserved. 
detection (data not shown). This result could indicate wide distribution of PRV-3 in Germany and suggests that further studies of prevalence are needed.

The PRV-1 and PRV-3 screenings presented in our study covered only a limited amount of animals. Furthermore, due to coinfections with $A$. salmonicida, the contribution of the viral infection to disease was more challenging to assess. Therefore, at this point, the epidemiologic importance of these viruses is difficult to evaluate for the German salmonid aquaculture and for the natural populations of Atlantic salmon. However, these findings confirm the large geographic distribution of piscine orthoreoviruses. Worldwide, aquaculture of salmonids is a significant source of animal protein for human consumption. Atlantic salmon and rainbow trout are the most popular salmonid species with a production of 3.14 million metric tonnes worldwide in 2015 (FAO, 2017) . Additionally, due to their high market value of nearly $\$ 15$ billion, the aquaculture of these fish species is important for the gross domestic product of several countries, including Norway and Chile (FAO, 2017). Piscine orthoreoviruses infection and diseases caused by them, could pose a challenge to the sustainable development of salmonid aquaculture worldwide. In this context, our findings should imply an increase in the awareness of PRV-1- and PRV-3-associated diseases in Atlantic salmon and rainbow trout populations. European diagnostic laboratories for aquatic animal health should include these infections in the diagnostic pool when investigating unexplained disease outbreaks in salmonid fish species.

\section{Acknowledgments:}

We would like to acknowledge the laboratory support provided by Ingo Hein and Timo Henneck.

\section{Conflict of interest statement:}

There is no potential conflict of interest.

\section{References:}

Adamek, M., H. Syakuri, S. Harris, K. Ł. Rakus, G. Brogden, M. Matras, I. Irnazarow and D. Steinhagen, 2013: Cyprinid herpesvirus 3 infection disrupts the skin barrier of common carp (Cyprinus carpio L.). Veterinary Microbiology, 162, 456-470.

Cartagena, J., C. Tambley, A. M. Sandino, E. Spencer and M. Tello, 2018: Detection of piscine orthoreovirus in farmed rainbow trout from Chile. Aquaculture, 493, 79-84.

Crane, M. and A. Hyatt, 2011: Viruses of Fish: An Overview of Significant Pathogens. Viruses, 3, 2025-2046.

Dereeper, A., V. Guignon, G. Blanc, S. Audic, S. Buffet, F. Chevenet, J. F. Dufayard, S. Guindon, V. Lefort, M. Lescot, J. M. Claverie and O. Gascuel, 2008: Phylogeny.fr: robust phylogenetic analysis for the nonspecialist. Nucleic Acids Resorces, 36 (Web Server issue), W465-W469.

Dhamotharan, K., N. Vendramin, T. Markussen, $\varnothing$. Wessel, A. Cuenca, I. Nyman, A. Olsen, T. Tengs, M. Krudtaa Dahle and E. Rimstad, 2018: Molecular and Antigenic Characterization of Piscine orthoreovirus (PRV) from Rainbow Trout (Oncorhynchus mykiss). Viruses, 10, 170.

European Commission, 2015: COMMISSION IMPLEMENTING DECISION (EU) 2015/1554 of 11 September 2015 laying down rules for the application of Directive 2006/88/EC as regards requirements for

This article is protected by copyright. All rights reserved. 
surveillance and diagnostic methods. Official Journal of the European Union, $L 247$

http://extwprlegs1.fao.org/docs/pdf/eur148538.pdf

FAO, 2017: FAO yearbook. Fishery and Aquaculture Statistics 2015. http://www.fao.org/3/a-i7989t.pdf.

Finstad, Ø. W., M. K. Dahle, T. H. Lindholm, I. B. Nyman, M. Løvoll, C. Wallace, C. M. Olsen, A. K. Storset and E. Rimstad, 2014: Piscine orthoreovirus (PRV) infects Atlantic salmon erythrocytes. Vet. Res., 45, 35.

Finstad, Ø. W., K. Falk, M. Løvoll, Ø. Evensen and E. Rimstad, 2012: Immunohistochemical detection of piscine reovirus (PRV) in hearts of Atlantic salmon coincide with the course of heart and skeletal muscle inflammation (HSMI). Vet. Res., 43, $27-27$.

Ganzhorn, J. and S. E. LaPatra, 1994: General Procedures for Virology. In: John C. Thoesen (Ed), Fish Health Blue Book, Number 4: Suggested Procedures for the Detection and Identification of Certain Finfish and Shellfish Pathogens. American Fisheries Society, Bethesda, Md.

Garseth, A. H., C. Fritsvold, M. Opheim, E. Skjerve and E. Biering, 2013: Piscine reovirus (PRV) in wild Atlantic salmon, Salmo salar L., and sea-trout, Salmo trutta L., in Norway. J Fish Dis, 36, 483-493.

Garver, K. A., G. D. Marty, S. N. Cockburn, J. Richard, L. M. Hawley, A. Muller, R. L. Thompson, M. K. Purcell and S. Saksida, 2016: Piscine reovirus, but not Jaundice Syndrome, was transmissible to Chinook Salmon, Oncorhynchus tshawytscha (Walbaum), Sockeye Salmon, Oncorhynchus nerka (Walbaum), and Atlantic Salmon, Salmo salar L. J Fish Dis, 39, 117-128.

Godoy, M. G., M. J. Kibenge, Y. Wang, R. Suarez, C. Leiva, F. Vallejos and F. S. Kibenge, 2016: First description of clinical presentation of piscine orthoreovirus (PRV) infections in salmonid aquaculture in Chile and identification of a second genotype (Genotype II) of PRV. Virol J, 13, 98.

Hauge, H., N. Vendramin, T. Taksdal, A. B. Olsen, O. Wessel, S. S. Mikkelsen, A. L. F. Alencar, N. J. Olesen and M. K. Dahle, 2017: Infection experiments with novel Piscine orthoreovirus from rainbow trout (Oncorhynchus mykiss) in salmonids. PloS one, 12, e0180293.

Kibenge, M. J., T. Iwamoto, Y. Wang, A. Morton, M. G. Godoy and F. S. Kibenge, 2013: Whole-genome analysis of piscine reovirus (PRV) shows PRV represents a new genus in family Reoviridae and its genome segment S1 sequences group it into two separate sub-genotypes. Virology Journal, 10, 230.

Kongtorp, R. T., A. Kjerstad, T. Taksdal, A. Guttvik and K. Falk, 2004: Heart and skeletal muscle inflammation in Atlantic salmon Salmo salar L: a new infectious disease. J Fish Dis, 27.

Lund, M., M. Krudtaa Dahle, G. Timmerhaus, M. Alarcon, M. Powell, V. Aspehaug, E. Rimstad and S. M. Jorgensen, 2017: Hypoxia tolerance and responses to hypoxic stress during heart and skeletal muscle inflammation in Atlantic salmon (Salmo salar). PloS one, 12, e0181109.

Marty, G. D., D. B. Morrison, J. Bidulka, T. Joseph and A. Siah, 2015: Piscine reovirus in wild and farmed salmonids in British Columbia, Canada: 1974-2013. J Fish Dis, 38, 713-728.

Mooney, J., E. Powell, C. Clabby and R. Powell, 1995: Detection of Aeromonas salmonicida in wild Atlantic salmon using a specific DNA probe test. Diseases of Aquatic Organisms, 21, 131-135.

Morton, A., R. Routledge, S. Hrushowy, M. Kibenge and F. Kibenge, 2017: The effect of exposure to farmed salmon on piscine orthoreovirus infection and fitness in wild Pacific salmon in British Columbia, Canada. PloS one, 12, e0188793.

Olsen, A. B., M. Hjortaas, T. Tengs, H. Hellberg and R. Johansen, 2015: First Description of a New Disease in Rainbow Trout (Oncorhynchus mykiss (Walbaum)) Similar to Heart and Skeletal Muscle Inflammation (HSMI) and Detection of a Gene Sequence Related to Piscine Orthoreovirus (PRV). PloS one, 10, e0131638.

Palacios, G., M. Lovoll, T. Tengs, M. Hornig and S. Hutchison, 2010: Heart and skeletal muscle inflammation of farmed salmon is associated with infection with a novel reovirus. PloS one, 5 .

Purcell, M. K., R. L. Powers, J. Evered, J. Kerwin, T. R. Meyers, B. Stewart and J. R. Winton, 2018: Molecular testing of adult Pacific salmon and trout (Oncorhynchus spp.) for several RNA viruses demonstrates widespread distribution of piscine orthoreovirus in Alaska and Washington. J Fish Dis, 41, 347-355.

Takano, T., A. Nawata, T. Sakai, T. Matsuyama, T. Ito, J. Kurita, S. Terashima, M. Yasuike, Y. Nakamura, A. Fujiwara, A. Kumagai and C. Nakayasu, 2016: Full-Genome Sequencing and Confirmation of the Causative Agent of Erythrocytic Inclusion Body Syndrome in Coho Salmon Identifies a New Type of Piscine Orthoreovirus. PloS one, 11, e0165424.

Wessel, O., S. Braaen, M. Alarcon, H. Haatveit, N. Roos, T. Markussen, T. Tengs, M. K. Dahle and E. Rimstad, 2017: Infection with purified Piscine orthoreovirus demonstrates a causal relationship with heart and skeletal muscle inflammation in Atlantic salmon. PloS one, 12, e0183781.

Wiik-Nielsen, J., M. Alarcon, B. B. Jensen, O. Haugland and A. B. Mikalsen, 2016: Viral co-infections in farmed Atlantic salmon, Salmo salar L., displaying myocarditis. J Fish Dis, 39, 1495-1507. 
.Figures:

Figure 1. Phylogenetic analysis of: (A) the nucleotide sequence encoding: the segment L1 PRV-1 from Germany (DH_747072017, GenBank ID: MG770489), Norway (NOR2012-V3621, GenBank ID: KY429945), Canada (B5690, GenBank ID: KX851983; B7274, GenBank ID: KX851982; BCJ31915_13, GenBank ID: KT429740; BCJ19943_13, GenBank ID: KT429730) and USA (WSKFH12_14, GenBank ID: KT429750), the tree was rooted using PRV2 (GenBank ID: LC145610) as outgroup; (B) the nucleotide sequence encoding the segment S1 of the sigma 3 protein of PRV-3 isolates from Germany (DH773072017; GenBank ID: MG770490), Norway (F4452013NOR, GenBank ID: LN680851) and Chile (C10/P2.2, GenBank ID: KX844962; C10/P3.1, GenBank ID: KX844961; C10/P3.2, GenBank ID: KX844960; C10/P4.2, GenBank ID: KX844959; VT12202013-CGA-2013-3, GenBank ID: KU131595; C10/P1.1, GenBank ID: KX844965; C10/P1.2, GenBank ID: KX844964; VT12202013CGA-2013-5, GenBank ID: KU131596) and PRV-1 isolate from Norway (1195Aaroy2007, GenBank ID: HG329893), the tree was rooted using PRV-2 (GenBank ID: LC145616) as outgroup. MrBayes phylogeny (Bayesian inference) was used with Markov Chain Monte Carlo parameters set-up to 10000 generations, with tree sampling every ten generations and burn-in of 250 trees sampled. The branch length is proportional to the number of substitutions per site. Branch supporting values are indicated with the number.

This article is protected by copyright. All rights reserved. 

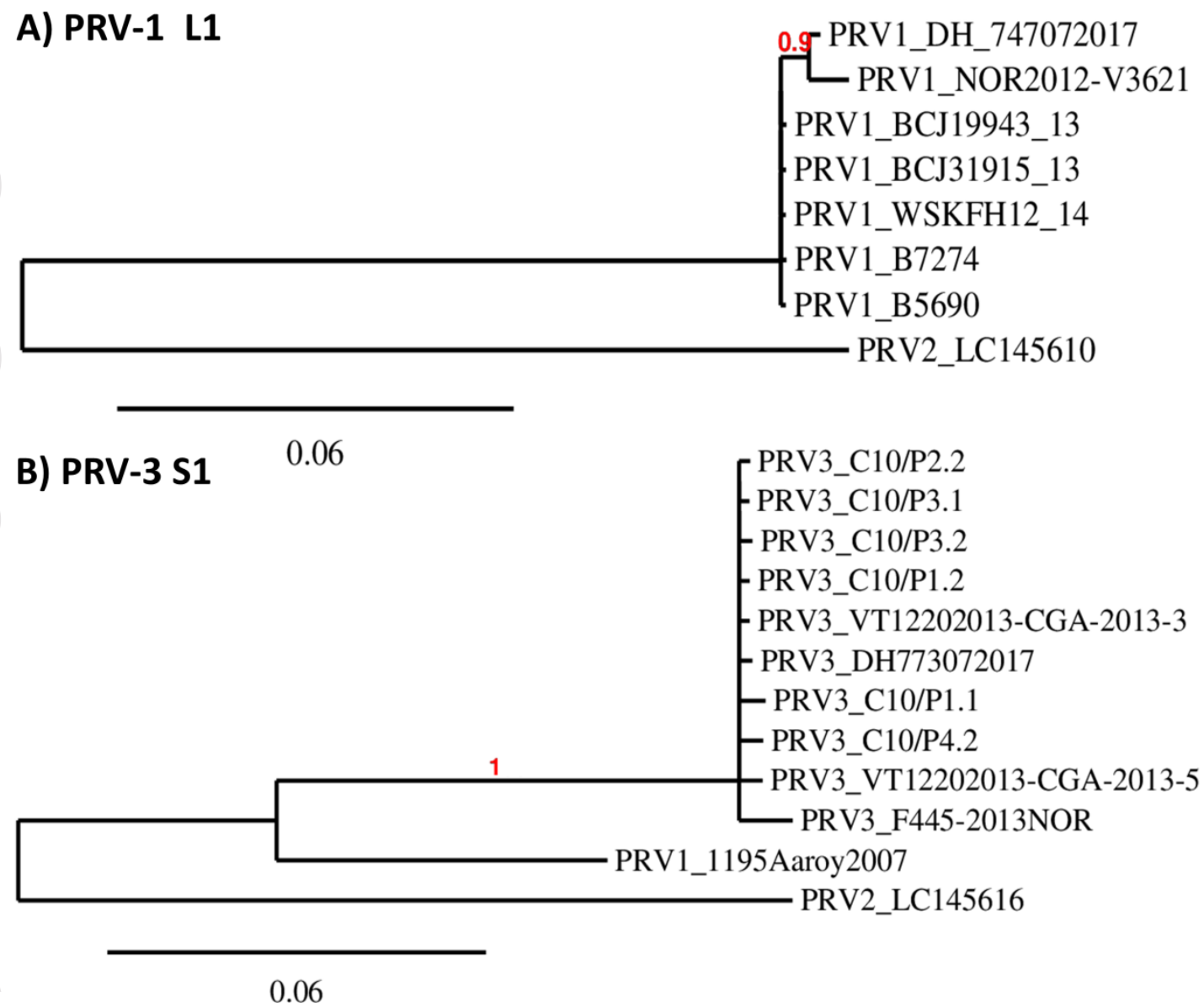